\title{
LOS USHNUS SOBRE HUACAS LOCALES: ANÁLISIS PRELIMINAR DE LOS USHNUS DEL DISTRITO DE OCROS, AYACUCHO
}

\author{
ANUOR Abel García Reyes ${ }^{1}$ \\ Universidad NACIONAL SAN CRISTÓBAL DE HUAMANGA \\ agarey14@gmail.com
}

\section{RESUMEN}

La presente investigación consiste en un análisis morfo-funcional y simbólico de los ushnus aislados que se hallan sobre huacas o apus de importancia local, denominados Pumaqawanqa y Huayna Pizarro. El propósito es aportar al conocimiento sobre las características geográficas y simbólicas que habrían influido para la instalación de ushnus aislados en el entorno geográfico del distrito de Ocros, su relación con el ecosistema adyacente y las actividades que tuvieron lugar en ellas. Asimismo, entender la estrategia de los incas al establecer estas estructuras sobre las deidades locales, su supremacía ante los grupos locales, como un tema para explicar la anexión del territorio Chanca bajo el poder del Tahuantinsuyo. En los últimos años, en la región de Ayacucho han sido presentados varios ushnus situados en espacios disímiles, las mismas que han sido clasificadas de acorde a su ubicación, tales como: en las plazas principales, en los tambos, en las inmediaciones de los santuarios, en la cima de las huacas locales, en las principales abras y en las inmediaciones de los campos de chaccu de vicuñas (Cavero 2015). Finalmente, nos enfocaremos en el sitio tipo de Huayna Pizarro, uno de los sitios de influencia Inca en medio de asentamientos Chanca y en mal estado de conservación.

Palabras clave: Ushnus aislados, arqueología del paisaje, huacas locales, apus tutelares, plataformas, cistas.

\section{ABSTRACT}

This research consists of a morpho- functional analysis of isolates ushnus that are on huacas or apus of local importance, called Pumaqawanqa and Huayna Pizarro. The purpose is to contribute to knowledge about the geographical and symbolic characteristics that have influenced for the installation of ushnus isolated in the geographical area Ocros district, its relationship with the immediate

1. Licenciado en Arqueología, Candidato a magister en Gestión del Patrimonio Cultural, Universidad Nacional Mayor de San Marcos. 
environment and the activities that took place in them. Also, understand the strategy of the Incas in establishing these structures on local deities, their supremacy to local groups such as a theme to explain the incorporation of the territory Chanca under the power of Tahuantinsuyo. In the ayacuchano territory the presence of ushnus have been classified according to the geographical, such as context: in the main squares in dairy farms in the vicinity of the sanctuaries, on top of local huacas, in the main open and in the vicinity of the campus chaccu vicuna (Cavero 2015). Finally, we will focus on the type of Huayna Pizarro site, one of the sites of Inca influence amid settlements Chanca and in poor condition.

KeYwoRDs: Ushnus isolated, landscape archeology, local huacas, apus tutelary, platforms, cistas.

\section{INTRODUCCIÓN}

En los años 2008 y 2012 fui parte de un proyecto de exploración e investigación de sitios arqueológicos enmarcados en la microcuenca del río Qaqamarca, distrito de Ocros-Ayacucho. Durante este proceso se prospectó en las inmediaciones del valle de Chumbes, lugar donde no existen referencias sobre la presencia de asentamientos propios del Horizonte Tardío y las publicaciones existentes tratan de manera sucinta sobre la importancia de los ushnus. En este espacio geográfico de clima variado se ha podido distinguir una secuencia ocupacional desde el Precerámico hasta el Horizonte Tardío, y sobre todo la presencia de haciendas coloniales agro-ganaderas en las localidades de Ccaccamarca y Occechipa, esta última formó parte de las propiedades de la familia del Mariscal Andrés Avelino Cáceres. La mayoría de los sitios arqueológicos del distrito de Ocros se hallan en condición de abandono por parte del Estado, también un aspecto imposible de controlar, pero sí de prevenir, corresponde a los eventos antrópicos y factores climáticos, que de una u otra forma vienen afectado paulatinamente los restos arqueológicos.

Hoy en día, los avances ocurridos en la caracterización y su correspondiente ubicación de los ushnus en contexto con el entorno geográfico vienen generando hipótesis sobre su nexo con las montañas sagradas, controladores del clima y por ende el éxito de la producción agro-ganadera. Los trabajos de campo van ampliando la cantidad y el conocimiento sobre el ushnu, las prospecciones arqueológicas han permitido identificar algunas plataformas ceremoniales en espacios aislados de la región ayacuchana; estas evidencias son recurrentes en la región, demostrando la importancia que tuvieron las montañas sagradas como Qarwarazu en el sur y Razuwillka en el norte. A pesar que el valle bajo de la cuenca del río Pampas fue densamente habitada en épocas prehispánicas, no existen mayores investigaciones pormenorizadas del tema precitado en el distrito de Ocros, de todos los trabajos consultados nadie hace referencia al ushnu de Huayna Pizarro e incluso la población local circundante desconoce su nombre - al parecer con la ocupación española en las haciendas de Ccaccamarca y Occechipa el culto andino fue paulatinamente extirpada para dar lugar a la veneración de santos católicos - solo algunas personas denominan al cerro como Huayna Pizarro (en este artículo emplearemos esta última denominación). Lo que si es cierto, el poblador ocrino mantiene el respeto y veneración a sus apus Pumaqawanqa, Huayna Pizarro y Huachulla, no por la existencia sobre ellas de las plataformas ushnus, sino lo perciben como un ente regulador del tiempo y protector de las personas y animales que se hallan circunscritos; ocasionalmente y en fechas determinadas la población acude a los cerros precitados a depositar el pagapu que consiste en la hoja de coca, cigarros, frutas, agua ardiente o cañazo, dulces y flores, la misma que colocan en un resquicio del apu tutelar.

El presente trabajo está circunscrito al análisis estructural, entorno geográfico y simbólico de tres ushnus (Huayna Pizarro, Torrechayoq y Pumaqawanqa) situados sobre una montaña que desde tiem- 
pos inmemoriales es considerada como una huaca de arraigo local de gran importancia; venerados y respetados en los pueblos de la jurisdicción del distrito de Ocros. Tomando como respaldo la arqueología del paisaje (Criado 1999, Hester, et.al. 1997, Renfrew y Bahn 1998), a través del cual se intenta esbozar acerca de las diversas concepciones que existieron en el pasado en relación a los componentes del paisaje circundante, tanto en la utilización material como a su interpretación simbólica. El significado de los espacios geográficos en sus diferentes manifestaciones y la percepción por parte del poblador andino fue ampliamente divulgado por cronistas de los siglos XVI y XVII.

Los Apus, en tanto poseedores de territorios con sus ocupantes, se convirtieron en iconos representativos para demarcar espacios culturales y fronteras étnicas con sus respectivas identidades, mientras una huaca o wak'a, en opinión de Mario Polia, "es un receptáculo de lo sagrado, es el cuerpo de una entidad espiritual: una piedra, una roca, árbol, cueva, etc., que contiene un espíritu" (Polia 1999: 107) y representa la manifestación sobrenatural de una entidad espiritual con poderes. Siendo Pumaqawanqa y Huayna Pizarro dos apus locales votivos de cierta importancia, condición aprovechada por los incas para someter a los grupos locales al edificar las plataformas ushnus sobre ellos, simbólicamente representaría la expresión imaginativa del poder con el objeto de intimidación e imposición a la población local a nuevas formas de prácticas ceremoniales. Se observa cierta diferencia en cuanto al acabado, entre las estructuras ubicadas en el sur y el norte ayacuchano; en el primer caso, las plataformas presentan una mampostería externa a base de piedras talladas, modificadas y canteadas. Mientras en el segundo caso, las estructuras fueron edificadas con piedras del lugar escogidas, presentado una mampostería rústica tipo pirca. Esta diferencia podría obedecer a la importancia de las montañas oraculares como Qarwarazu (oráculo estatal) al sur y Razuwillka (oráculo regional) al norte. Y los ushnus probablemente habría sido una especie de huaca de alcance local vinculada con el culto al complejo montañas-fertilidad de la tierra y una relación cumbre-ushnu.

Contextualmente, cerca de estos ushnus aislados de Ocros se distingue la presencia del camino prehispánico o Qhapaq Ñan que tendrían una estrecha relación con estas estructuras, pues se hallan estratégicamente situados en las abras naturales (Torrechayuq) que configura la cadena de montaña del nevado Razuwillka. Sobre la segunda plataforma del ushnu de Huayna Pizarro se identificaron cistas elaboradas de forma circular y corte cilíndrica, la presencia de estos elementos en un ushnu hasta el momento no han sido citados, podría tratarse de un sitio atípico con estas características en la región. Al interior de estas estructuras no se han hallado material cultural (cerámica, textiles o restos óseos), podría tratarse de un espacio donde depositaron ofrendas o pagos a los apus tutelares; pero también existe la posibilidad de ser tumbas relacionados al ritual del capac hucha o capacocha.

Finalmente, está en manos de las instituciones del Estado en velar por la salvaguardia de los ushnus aislados, que por su ubicación es propenso a ser destruido por manos inescrupulosas; proponiendo proyectos y programas de identificación, protección y puesta en uso social de estos recursos culturales, siguiendo las directrices de la legislación y con el asesoramiento técnico especializado. Es preciso alcanzar, para darle continuidad a las actuaciones, la integración de los técnicos o gestores culturales y la comunidad. Para ello, son necesarias medidas de sensibilización a la población, ya que se requiere dar a conocer a sus legítimos beneficiarios.

\section{UbicACIÓN DEL ÁreA dE EsTUdio}

El área de estudio se localiza al sureste de la capital de la región de Ayacucho, entre las coorde-

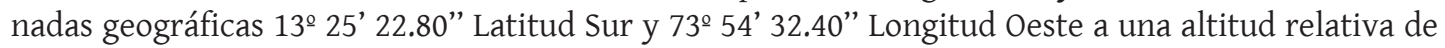
4,103 m.s.n.m. Los ushnus registrados se sitúan en la cima de la cadena de montaña que da origen a dos microcuencas denominadas Qaqamarca y Ocros, que a la vez se halla en la margen izquierda de la cuenca baja del río Pampas a $90 \mathrm{~km}$ sureste de la capital de la región (Fig. 1). El acceso a los sitios es 
relativamente fácil, se realiza mediante dos rutas: la primera, mediante una carretera asfaltada de 90 km que es un tramo de la longitudinal Ayacucho-Andahuaylas-Cuzco; la otra vía es de Ayacucho en dirección sureste por la vía Huatatas - Tambillo -Acocro hasta la altura de Sillarumi y Tintaypampa. De este lugar se accede a pie siguiendo la cresta del cerro Pumaqawanqa hasta los ushnus de Pumaqawanqa y Torrechayoq, y hacia el sur a una distancia de $1 \mathrm{~km}$ se halla el ushnu de Huayna Pizarro.

Políticamente pertenece al distrito de Ocros, provincia de Huamanga y región de Ayacucho. El límite distrital comprende: por el sur, con el distrito de Concepción (provincia de Vilcashuamán); por el norte, con el distrito de Luis Carranza (provincia de La Mar); por el este, con la provincia de Chincheros - región de Apurímac; y hacia el oeste, con el distrito de Acocro (provincia de Huamanga).

\section{Características Geográficas y Ecológicas}

Los ushnus registrados en el ámbito del distrito de Ocros se hallan en un espacio físico altoandino sobre la montaña denominada Pumaqawanqa ${ }^{2}$ que viene a ser uno de los contrafuertes que se desprenden de la cordillera occidental de los Andes, perteneciente a la cadena montañosa de Razuwillka. En la cima se hallan extensas pampas con pastos altos andinos como el ichu y por el este se localiza una cuenca profunda con escasa área marginal en las correntías del río Pampas de topografía accidentada con grandes acantilados.

Región Puna 4100 a 4800 msnm. Conocida como Jalca (Pulgar Vidal 1981), está conformado por el altiplano andino, declives escalonados, pampas humedales de carácter de bofedales y los cerros más altos. El clima es muy frío y húmedo, con viento helado y lluvias o granizo. La flora está constituida por arbustos achaparrados donde el ichu (Stypa ichu) es la biomasa de verdor clásico, pastizal importante para la ganadería altoandina como la llama (Lama glama), alpaca (Lama pacus), vicuña (Vicugna vicugna), etc. Existen algunas plantas arbustivas de tallo mediano como la cebadilla (Avena factua), espiguilla (Bounteloua rasemosa), taya (Lepidophyllum), quenwa (Polilepsis incana). Asimismo, podemos incluir a los animales domésticos entre los que se incluyen fundamentalmente los vacunos. Actualmente en esta zona no hay una población estable debido a la altura y el frío, solo es utilizado como campos de pastoreo y como estancias durante la siembra y cosecha, a ello se agrega la actividad agrícola de secano.

2. El significado de Pumaqawanqa ha sido descrito como "Puma ccahuancca" por Juan de Mata Peralta (1995: 8) en las Tradiciones de Huamanga; la historia en torno al cerro comienza así: "Eran los primeros días de septiembre de 1533, el cacique de Conchopata mandaba a un indio chasqui a dar algunas noticias a los orejones del Cuzco sobre las riquezas recolectadas para el rescate del Inca Atahualpa. El chasqui avanzaba jadeante la cuesta de Pumaccahuancca y se encuentra con una comitiva de indios del Cuzco que conducían ingente riqueza de oro y plata en piaras de llamas; el chasqui les informa que el Inca ya había sido ajusticiado. Al oír esta noticia ordenan cavar un hoyo de tres metros de profundidad y allí echaron toda la riqueza y cubrieron con la misma tierra. Uno de los conductores le interpela al noble indio, y le dice: ccapacc, ¿pitacc ccahuancca? El jefe le contesta: Puma ccahuancca; es decir, que el puma cuidará. Para tal efecto, cerca de la fosa del entierro existe un cerro que tiene la forma de un puma. He aquí el origen del nombre de aquel lugar. Y no se sabe hasta la fecha, si existirán todavía esas riquezas enterradas o quizás lo hayan retirado...aquella roca en forma de puma, está entre las ultimas que se notan para comenzar la bajada de Puma ccahuancca hacia Ocros, de aquellas alturas se tiene un panorama hermoso al ver el valle hacia la bajada de Yauricucho...". Juan de Mata Peralta. (1995). Las Tradiciones de Huamanga. Tomo I, Vol. I. Ediciones Grafica N\&R. Ayacucho 


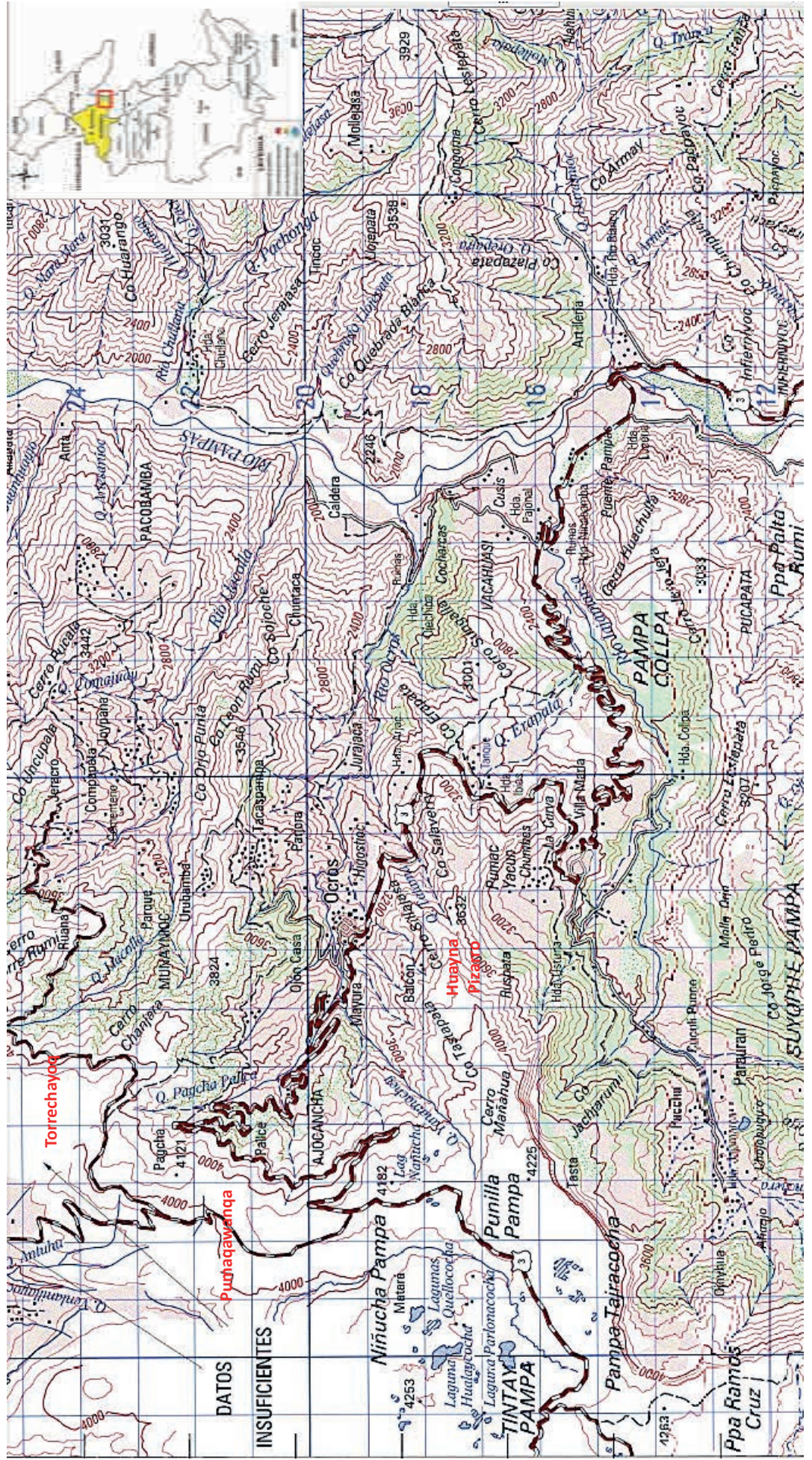




\section{HidROGRAFÍA}

El área de estudio presenta una hidrografía con un potencial que incluye riachuelos, lagunas, ojos de agua, etc., ocupa un espacio donde confluyen las micro-cuencas de los ríos Qaqamarca y Ocros que vierten sus aguas en el río Pampas (Fig. 2). El río Qaqamarca, cuya naciente se ubica al noreste del centro poblado de Ccaccamarca, orienta su recorrido de oeste a este y durante su trayecto atraviesa por diversos pisos ecológicos que van desde los 4,400 hasta los 1,900 m.s.n.m, desembocando sus aguas en el río Pampas. Este río forma un extenso valle que se caracteriza por poseer tierras fértiles de alta producción agrícola, una riqueza de su patrimonio cultural (material e inmaterial) que son evidencia de su potencial económico e histórico. Mientras el río Ocros nace en las alturas del cerro Pumaqawanqa y va tomando forma a la altura de la comunidad de Pallqa, y mantiene una forma uniforme hasta la altura de la localidad de Puncos; discurre sus aguas en dirección oeste a este, a la altura de la localidad de Parccora, el cauce tiende a ser algo estrecho y a profundizarse hacia el este, donde muestra cambios bruscos de desnivel a corta distancia y en donde no hay signos de áreas de cultivo, sino hasta la planicie de Occechipa y Llaweqmarca.

\section{ANTECEDENTES DE INVESTIGACIÓN}

En los últimos años ha sido notorio el incremento de las investigaciones relacionadas a los ushnus en la región de Ayacucho, y particularmente se ha prestado atención al registro de los ushnus aislados situados -en su mayoría- en la cima de las montañas distribuidos en casi todas las provincias de Ayacucho.

Las primeras informaciones acerca de los ushnus fueron proporcionadas por los cronistas, específicamente del usnu de Bilcas Cieza de León 1947 [1548]; Albornoz 1967:.24 [1582]; Santa Cruz Pachacuti 1995:92 [1613: fol. 32r.]; Guamán Poma 1980:452 [1615: fol. 445[447], entre otros; quienes plantean diversas interpretaciones sobre la naturaleza de los ushnus. En la segunda mitad del siglo XIX, los viajeros extranjeros George Squier (1892 y 1868), Charles Wiener (1880) y Leoncio Angrand (1897), describen e ilustran con grabados el ushnu de Vilcashuamán y algunas evidencias prehispánicas adyacentes a la red vial Inca o Qhapaq Ñan. En la etapa de la arqueología científica destacan los trabajos de Reagal (1936); Lumbreras (1959,1974); Strube (1963); Harth-Terré (1964); Gasparini y Margolies (1977); Gonzales Carré et. al. (1981); Zuidema (1989); Hyslop (1990); el Proyecto Qhapaq Ñan del Instituto Nacional de Cultura (2002, 2004 y 2005). La importancia arqueológica de los ushnus aislados en Ayacucho ha sido reconocida desde mediados del siglo XX, Carrera, Farfán y Gonzales (1945/1946) describen el ushnu de Huarmichayoc; Ladrón de Guevara (1959) reporta el ushnu de Inkapirqa en Quinua; posteriormente Valdez (2009) en el cerro Bañico; Meddens y Vivanco (2003, 2007 y 2008) trabajaron en once ushnus situados en algunas provincias de la región de Ayacucho; Cavero (2005, 2010) identificó ushnus aislados en las provincias de Lucanas; Lecoq y Deodat (2008) en Chungui-La Mar. En algunos casos incluyeron excavaciones y en consenso definen que estas estructuras fueron construidos en forma aislada en las partes altas de los cerros, asociados a los caminos del sistema vial Inca o Qhapaq ñan.

Consecutivamente, en los últimos años el número de ushnus muestreados en Ayacucho se ha incrementado gracias a los trabajos de prospección efectuados por egresados de la Universidad de Huamanga dentro del marco de Prácticas pre-profesionales, por ejemplo Mendoza (2007) en Atenqocha de Vilcas; García (2009, 2012) en Huayna Pizarro de Ocros; Añanca y Canchari (2009) en Intihuatana I \& II de Chungui; Gómez (2009) en Inkaraqay de Sivia; Quispe y Rojas (2010) en el ushnu de Huallan, etc.

A pesar que el valle bajo de la cuenca del río Pampas fue densamente habitada en épocas prehis- 


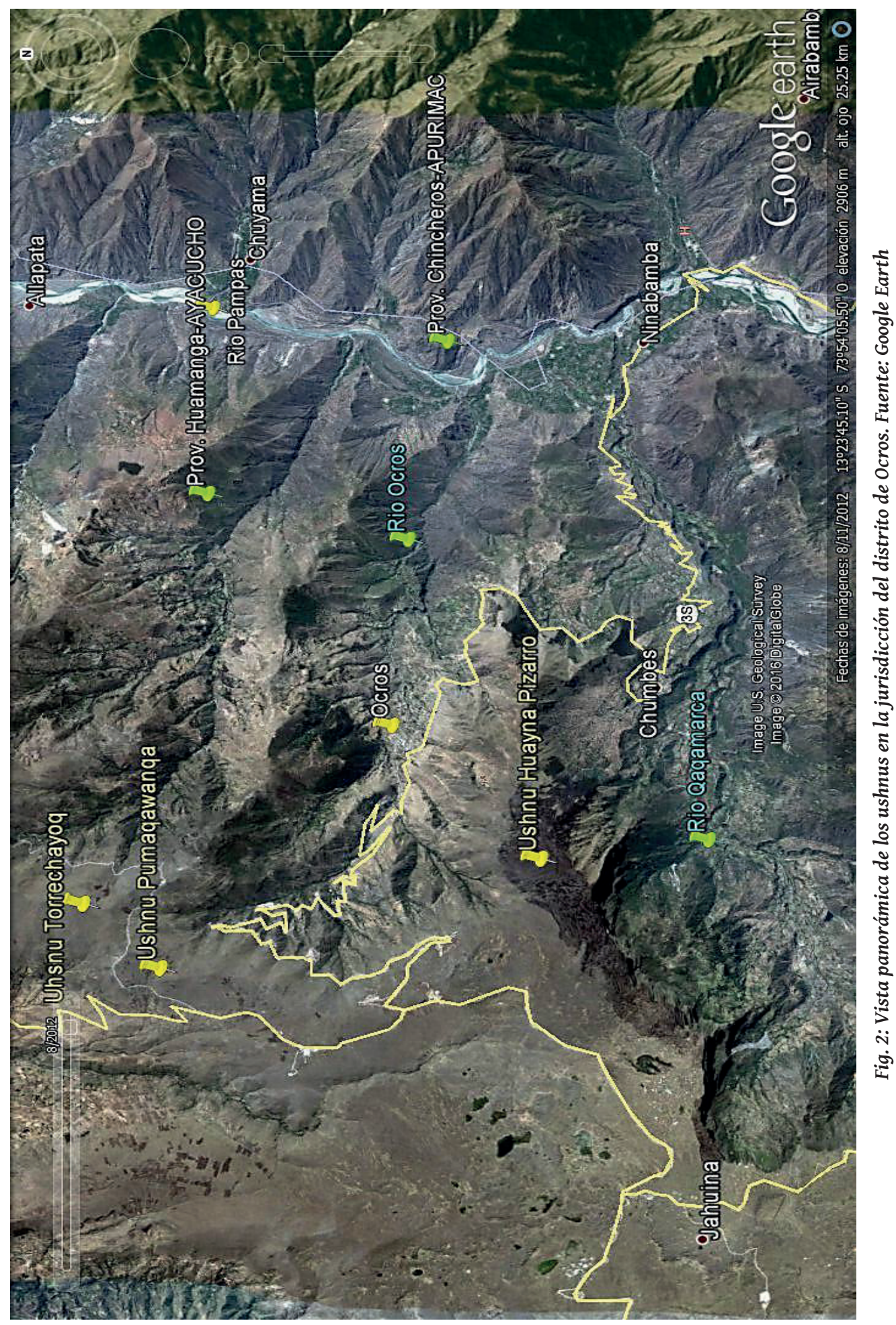


pánicas, no existen mayores investigaciones pormenorizadas del tema precitado en el distrito de Ocros, de todos los trabajos consultados nadie hace referencia al ushnu de Huayna Pizarro e incluso la población local circundante desconoce su nombre - al parecer con la ocupación española en las haciendas de Ccaccamarca y Occechipa el culto andino fue paulatinamente extirpado para dar lugar a la veneración de santos católicos - solo algunas personas denominan al cerro como Huayna Pizarro (en este artículo emplearemos esta última denominación).

\section{Definición, Significado y Tipología de Ushnu}

El término ushnu tiene una gran variedad de definiciones como: trono del inca, el lugar del capac hucha o sacrificio humano (Guamán Poma 1980 [1583]); pileta de piedra o de oro donde hacían sacrificios en honor al sol (Albornoz 1989 [1581-1585]; o como un asiento de piedra, o un mojón cuando es un asiento de piedra de gran tamaño (González Holguín 1952 [1608]); un altar de piedra que llamaban osno para sus sacrificios (Anónimo 1968 [1580-1621]). Mientras que Bauer (1998) manifiesta que el ushnu es una plataforma o pirámide trunca con un acceso o escalera que conducía a la parte superior en el cual podía existir un asiento o un bloque de roca. Para Pino (2004) el ushnu tenía un concepto ceremonial que posiblemente significaba "el lugar donde se ofrendaban los líquidos o lugares de libaciones”. Vitry (2008) sugiere que fue un altar consistente en una pirámide sólida, escalonada y trunca, donde el Inca o su representante de la nobleza se posaban; la definición acertada de ushnu seria “...un conducto vertical parecido a un eje mundo, que une simbólicamente el cielo, la tierra y el inframundo, los ancestros terrenales y la huacas con los cosmos." (Zuidema 1980, citado por Meddens et. al. 2009:282).

La primera referencia de la palabra ushnu la entrega Santo Tomás en su diccionario de 1560 donde define Ozño u osño; luego en 1568 Cristóbal de Albornoz identifica la palabra Usno como el lugar donde el Inca literalmente bebía al Sol. Su respectiva etimología y procedencia del concepto es discutible, Zuidema (1989) sospecha que la palabra ushnu no fue original del Cusco, pero los incas le dieron mucha importancia como concepto político; mientras que Bueno (2010) discrepa al manifestar que el ushnu es de invención originaria cusqueña. Al respecto, Pino (2004) concuerda con Zuidema al considerar que la posible "área nativa" del concepto ushnu está en la sierra central del Perú, cuyo probable significado primario del mismo es "lugar donde hay puras piedras o cascajo donde se filtra el agua”. Para el caso de Ayacucho, Cavero (2010) manifiesta que en la tradición oral de los pastores de la puna de Lucanas y Huancasancos, la palabra "ushnu" no es común sino que lo llaman "inkapamisan" o "mesa del inca", igual significado encontró Matos (1994) en la comunidad de Pari; mientras que en la parte norte de Ayacucho estas estructuras ceremoniales son considerados como Intiwatana, Limaqawarina o Inkaptianan. Es discutible su origen y significado, no hay un consenso en cuanto a la etimología, probablemente esta palabra es originaria de la sierra central y centro-sur (o Chinchaysuyu en la época Inca); si contextualizamos el espacio geográfico ayacuchano vamos a encontrar algunos pueblos que llevan el nombre de Osno (como en Tambo). Mientras que en las comunidades del distrito de Ocros la palabra "ushnu" es sinónimo de "waspi" o "alcanzo", es decir, lugar donde emana vapor de la tierra que produce malestar en la persona, si no es curado a tiempo produce la muerte, y estos lugares generalmente son puquiales o cimas de los cerros encantados y peligrosos.

De acuerdo a la observación y análisis de las características físicas de las estructuras ushnu presentes en el área del Tahuantinsuyu se propone tres tipos: 1.- Los ushnus de forma piramidal trunca. Se trata de una estructura arquitectónica de planta ortogonal y con plataformas superpuestas de forma piramidal (que pueden ser de 2 a más), sólida, escalonada y truncada con peldaños intermedios. Por ejemplo el ushnu de Vilcashuamán. 2.- Los ushnus de una sola plataforma o repisas. Están 
conformados por una sola plataforma de pequeña o mediana dimensión a modo de un bloque sólido e independiente al interior de una plaza o en lugares aislados, se accede por una escalinata o por una rampa en la costa, el material usado es la piedra o adobe. Como ejemplo se tiene al ushnu de Huanucopampa, Huaycán de Pariachi, Ilakata, etc. 3.- Los ushnus sobre mojón o roca. Estaba dominada por un enorme peñasco emplazado en un punto topográfico prominente, normalmente este peñasco fue enmarcado con dos líneas de plataformas realizadas con piedras de formas regulares, algunas de ellas con canteado expeditivo donde se incluía una rampa para ascender a la cúspide plana de la gran roca. Se halla con más frecuencia en el área meridional del imperio como: Ampajango 2 al noroeste argentino, Incallakta en Bolivia, etc. (Fig. 03)
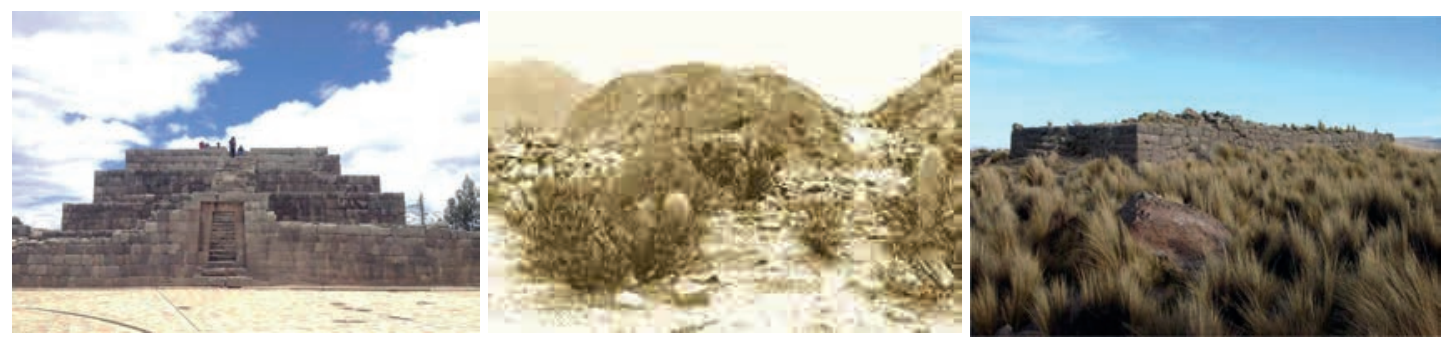

Fig. 03: Tres tipos de ushnus presentes en el Tahuantinsuyo, como ejemplo están los ushnus de Vilcashuamán, Wamanillo y Ampajango2 (Cavero 2010, Tarragó et. al. 2005).

El primer tipo de ushnu sintetizaría metafóricamente a la montaña y los andenes, tal como sugiere Morris (1991), donde la montaña sagrada está representada por la pirámide y los andenes por los terraplenes superpuestos que representaban la verticalidad andina entre el kay pacha, uku pacha y hanan pacha (Meddens et. al. 2009). Y ¿los dos tipos de estructuras restantes qué representaron? ¿En realidad eran ushnus? También fueron estructuras ceremoniales de importancia en cuya cima - de la plataforma o mojón - estaban situados los dioses y sus representantes (los funcionarios estatales); mientras en la parte baja, la gente del común. En consenso, los autores declaran que en estas estructuras se llevaron a cabo ceremonias orientadas a actividades comunitarias dirigidas hacia las divinidades, que incluía un reconocimiento a la autoridad de los oficiantes y legitimaba la estructura de poder.

\section{IMPORTANCIA CULTURAL DE LOS USHNUS O PLATAFORMAS CEREMONIALES}

La presencia de los ushnus en el Tahuantinsuyu está relacionado al aspecto religioso que estaba presente para la consolidación del poder político cusqueño en las provincias, donde el Estado Inca utilizó la ideología religiosa para incorporar a las deidades locales y alzando las plataformas en lugares sagrados locales; revelando la imposición estatal a los naturales del sistema religioso, la organización económica y una política coercitiva de sumisión (Vivanco y Meddens 2010).

Primigeniamente en las crónicas se menciona sobre la importancia del ushnu tal como Guaman Poma lo dice: "Llego a Bilcas Guaman y subió al aciento y gradas unhnu del inca y anci fue rercivida [sic] con el mismo inga todos los señores principales y mando a subir al más viejo y principal al ushnu..." (Guaman Poma 1613, citado por Cavero 2005: 105). La importancia del ushnu en la vida social, militar, político, económico y religioso del Tahuantinsuyu han sido propuestas por diversos investigadores, al respecto Pino (2005) considera que en el área del Chinchaycocha los ushnus difieren en forma y tamaño, pero coinciden en la posición casi central del asentamiento, apoya la idea del ushnu como "centro" a Hyslop (1990) este último considera que estas estructuras no solo serían el lugar 
destinado a ofrendas liquidas sino que, se relacionaría a sacrificios de niños (capacocha) y otro tipo de ofrendas; mientras Matos (1994) percibe que los ushnus habrían jugado un papel muy importante desde el comienzo de la planificación y el diseño de la ciudad. Finalmente Cavero (2010), refiere que la elección del lugar en el que construyeron los ushnus no fue al azar, respondería a una planificación estatal Inca con fines de garantizar la unidad socio-política del Tahuantinsuyu.

El proceso de expansión territorial de los incas en Ayacucho implicó la anexión de espacios geográficos nuevos y desconocidos -que seguramente entraron en franca oposición con los grupos locales que defendieron su territorio habitado y sobre todo su espacio sagrado- que aportaron a la transformación del paisaje de acorde a la cosmovisión del grupo étnico dominante (Inca) que impusieron la edificación de estructuras ushnu sobre las huacas locales de los grupos dominados (¿chancas?), cuyo propósito fue la imposición de poder. En este contexto usufructuaron las tierras fértiles situadas en ambas microcuencas (Qaqamarca y Ocros), levantaron plataformas en lugares estratégicos y aislados de poblados como son las abras de los caminos principales, sobre las huacas locales y en las inmediaciones de los campos para la fertilidad de los camélidos (Cavero 2015).

\section{ANÁLISIS SITUACIONAL DE LOS USHNUS DEL DISTRITO DE OCROS}

El presente capítulo pretende efectuar un análisis de las características arquitectónicas y formales de los ushnus denominados Pumaqawanqa, Torrechayoq y Huayna Pizarro que se hallan en las partes altas de la montaña que circunda la cuenca baja del río Pampas. Al mismo tiempo, se apela a los resultados de los datos arqueológicos propuestos por trabajos efectuados en la región de Ayacucho que ha permitido conocer su ubicación, y algunas características funcionales y significativas de estas estructuras de menor proporción que su contraparte localizada en Vilcashuamán. Por otro lado, el estado de conservación de los ushnus aislados es delicado, debido a los agentes antrópicos, agrícola intensiva, el pastoreo extensivo y fenómenos climáticos, y sobre todo por el desinterés de las autoridades en velar por su salvaguardia.

\section{EL USHNU DE HUAYNA PIZARRO}

Ubicación geográfica: Se ubica al oeste del Centro Poblado de Chumbes, en la cadena de montaña llamada Pumaqawanqa que viene a ser uno de los contrafuertes conexa a la cadena montañosa de Razuwillka. Sus coordenadas son: 0615067 E y $8516707 \mathrm{~N}$ a 4,103 msnm.

Acceso: Se llega al lugar siguiendo el camino de herradura que va desde el pueblo de Chumbes hacia Ayacucho y viceversa que convergen en la pampa San Pedro, de allí se toma un desvío en dirección suroeste para recorrer una distancia de $500 \mathrm{~m}$.

Ubicación política: Santa Isabel de Chumbes, distrito de Ocros, Provincia de Huamanga.

№ de plataformas y acceso: doble plataforma /al oeste

Dimensiones: $19 \mathrm{~m}$ x $15 \mathrm{~m}$ y $1.20 \mathrm{~m}$ de alto. / $11 \mathrm{~m} \mathrm{x} 10 \mathrm{~m}$ y $0.50 \mathrm{~cm}$ de alto.

Descripción: se trata de una plataforma ceremonial de forma piramidal trunca, de corte rectangular orientada en dirección sur a norte, está ubicado en la parte alta del cerro epónimo (Fig. 4-5) sobre una pequeña planicie existente desde donde se tiene magnifica vista panorámica de la cuenca baja del río Pampas. Está compuesta por dos plataformas superpuestas en pleno proceso de destrucción, sin embargo se puede observar que el acabado de sus muros es de aparejo rústico; en base a su diseño y elementos arquitectónicos definimos el ushnu de la siguiente manera: 
Plataformas: La primera plataforma, tiene $19 \mathrm{~m}$ de largo por $15 \mathrm{~m}$ de ancho, una altura que oscila entre la mínima de $0.30 \mathrm{~m}$ y la máxima de $1.20 \mathrm{~m}$, el muro es de doble hilada y cuyo espesor es de $0.70 \mathrm{~m}$, construidos con piedras de campo compuesto de lajas extraídas de una cantera ubicada al este del ushnu, son de tamaños variados y están unidos con barro, presenta un acabado de mampostería simple y rústica. Impregnadas en el muro se ven raíces y raicillas de gramíneas alto andinas como el ichu.

La segunda plataforma, tiene $11 \mathrm{~m}$ de largo por $10 \mathrm{~m}$ de ancho, la altura varía entre $0.30 \mathrm{~m}$ como mínimo y la máxima de $0.50 \mathrm{~m}$, actualmente poco visible pero a diferencia de la primera plataforma, el muro tiene un ancho de $0.93 \mathrm{~m}$ y de doble hilada, construida con piedras de campo y algunas lajas de andesita. El perfil externo e interno muestra un aparejo simple debido a que las piedras fueron colocadas de caras planas y unidas con barro; las piedras están colocadas en hiladas horizontales superpuestas una sobre otra, impregnadas entre las uniones se hallan gramíneas alto andinas como el ichu.

Escalinata y tiana: No fue posible ubicar estos componentes debido a la mala conservación de la estructura, solo se percibe las improntas de lo que posiblemente haya sido las escalinatas que se adosada a la primera plataforma, sobre esta última se aprecian dos saywas dispuestos verticalmente que fueron erigidas con piedras caídas del ushnu.

Cistas: se trata de cuatro cistas circulares situados sobre la segunda plataforma, tres de las cuales presentan huellas de disturbación y están cubiertas por escombros, la cuarta cista y la única que internamente conserva buena parte de su integridad constructiva. Presenta una estructura de piedra de campo seleccionadas y algunas lajas de andesita de color gris, unidas con barro. Tiene una forma circular y de corte una forma cilíndrica, cuyo diámetro es de $1 \mathrm{~m}$ y una profundidad de $1.40 \mathrm{~m}$, al interior no se hallaron elementos asociados.

Tipología constructiva: se basa en el uso de piedra de campo y lajas extraídas de la cantera que se haya a escasos $50 \mathrm{~m}$ del lugar, primordialmente conserva la mampostería de tradición local, más conocida como pirca o perqa. En la construcción de este ushnu no existe indicio alguno del uso de la piedra labrada al estilo cuzqueño, al contrario las piedras usadas presentan tamaños variados y formas irregulares con las aristas vivas; materiales que fueron asentados en hiladas relativamente horizontales, tendiendo a colocarlas verticalmente y mostrando las caras planas hacia el paramento externo del muro de c/u de las plataformas.

Elementos asociados: hacia el este, se adosado al ushnu una estructura en forma de "D" de $19 \mathrm{~m}$ de largo por $15.5 \mathrm{~m}$ de ancho, elaboradas con piedras de campo sin ningún tipo de argamasa o pircado en seco; se trata de una construcción posterior que habría cumplido la función de albergar a camélidos altoandinos como la vicuña. Asimismo, se ha divisado fragmentos de basalto, lajas de andesita los cuales no presentan huellas de talla; escaso material cultural como cerámica. Este lugar es un punto estratégico y a la vez de gran altura en relación a los otros sitios arqueológicos, se caracteriza por poseer hacia el lado noroeste un único acceso, todo el sector se encuentra delimitado y fortificado naturalmente por peñas de difícil accesibilidad, en cuya base se hallan cierta cantidad de estructuras funerarias que datan del Periodo Intermedio Tardío (ver figs. 6-14). 
Filiación Cultural: Horizonte Tardío.

Estado de conservación: es mala, la parte superior de este ushnu fue paulatinamente destruida por los buscadores de tesoros que emprendieron una búsqueda inescrupulosa a costa de la destrucción del patrimonio cultural. Muy cerca a este ushnu se emplaza un camino moderno que fue construido por los hacendados de La Colpa, según los comuneros de Chumbes, los hacendados tenían constantes enfrentamientos con la comunidad por la posesión de tierras, razón por la que la población restringe el libre tránsito a los hacendados por la vía principal que se desplaza por el pueblo de Chumbes. Posiblemente fueron los responsables de la destrucción del ushnu.

Registrado por: García Reyes (2009)
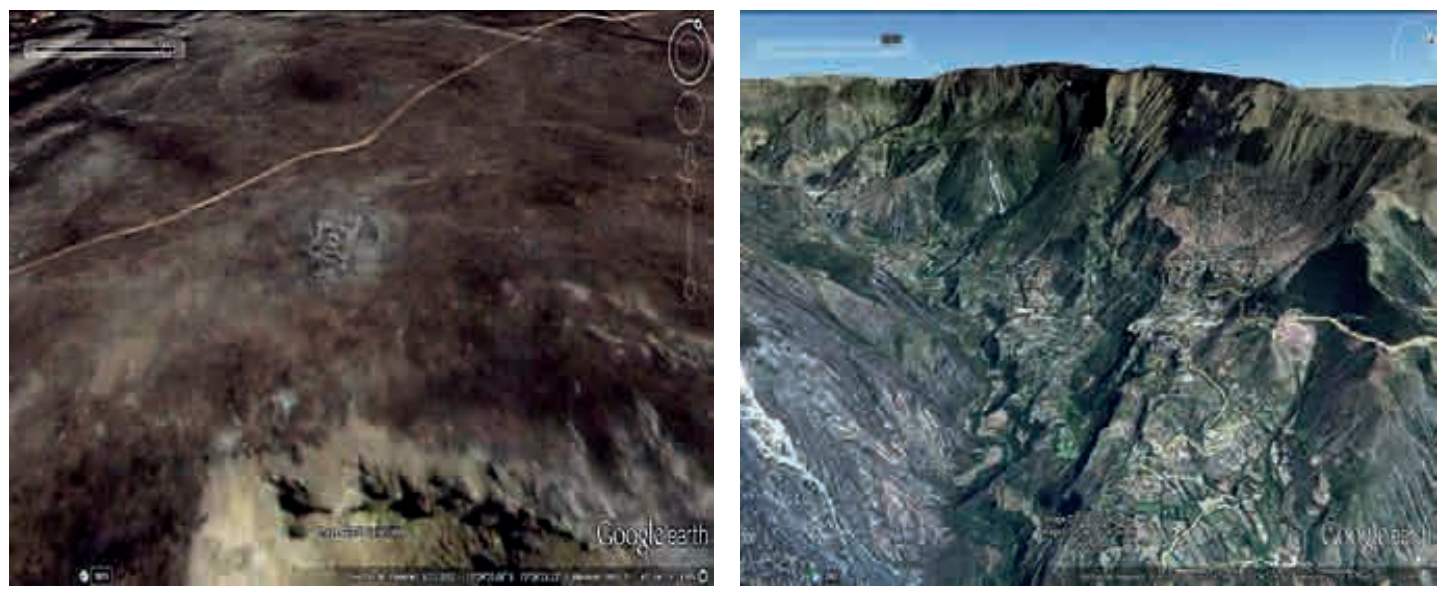

Fotos 4-5: Vista satelital del ushnu Huayna Pizarro. Derecha, vista del ushnu desde el valle de Chumbes.

\section{EL USHNU DE PUMAQAWANQA}

Ubicación geográfica: se ubica en la cima y muy cerca al abra de la cadena de montaña del cerro epónimo. Sus coordenadas son: 3²1'19.03” s y 7357’04.44” a 4035 m.s.n.m

Toponimia: es una palabra quechua compuesta de: puma= felino y qawanqa=el que ve o mira, de modo que significa "el puma lo va a ver".

Ubicación política: Comunidad de San Juan de Ocros, distrito de Ocros - Huamanga.

Acceso: se accede por el sur, partiendo de la carretera de Sillarumi cuesta arriba por la cresta del cerro epónimo; y desde el pueblo de Ocros por un camino antiguo hasta arribar al abra desde donde se perciben los ushnus de Pumaqawanqa y Torrechayuq (Fig. 16).

№ de plataformas y acceso: una plataforma /ausente

Dimensiones: $16 \mathrm{~m}$ x $10 \mathrm{~m}$ y $0.80 \mathrm{~m}$ de alto.

Tipo de mampostería: acabado rústico o pirca

Descripción: es una estructura de forma rectangular de una sola plataforma que se emplaza en la cresta más alta del cerro epónimo, ha sido construida a base de piedras semicanteadas porque han sido seleccionadas y colocadas de caras planas de diferentes tamaños y unidas con mortero de barro, 

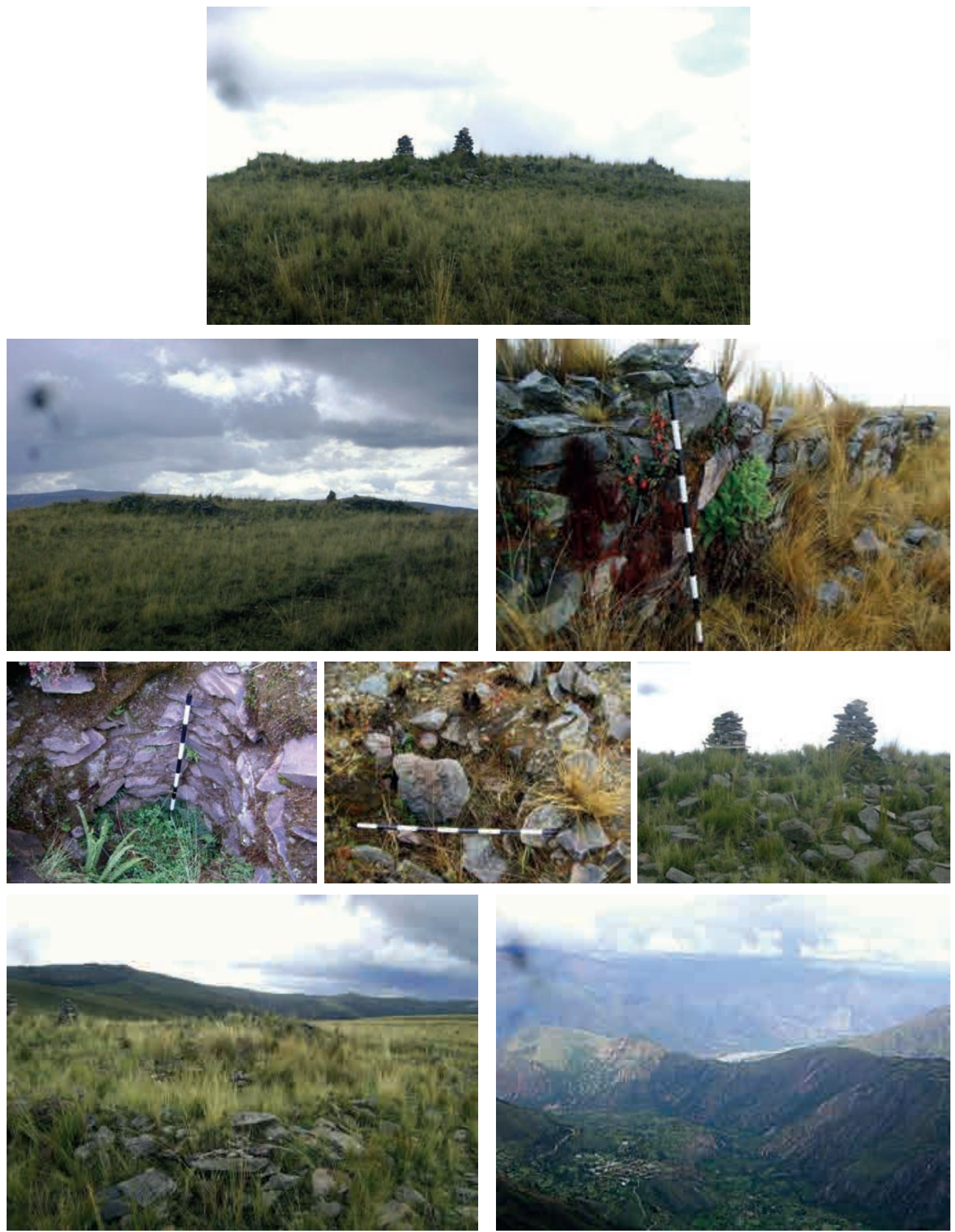

Figs. 6-13: Vista de las características generales del ushnu Huayna Pizarro, se aprecia las cistas, saywa y vista de los apus Pumaqawanqa y Huachulla en la cuenca baja del Pampas. Fotos: Abel García 


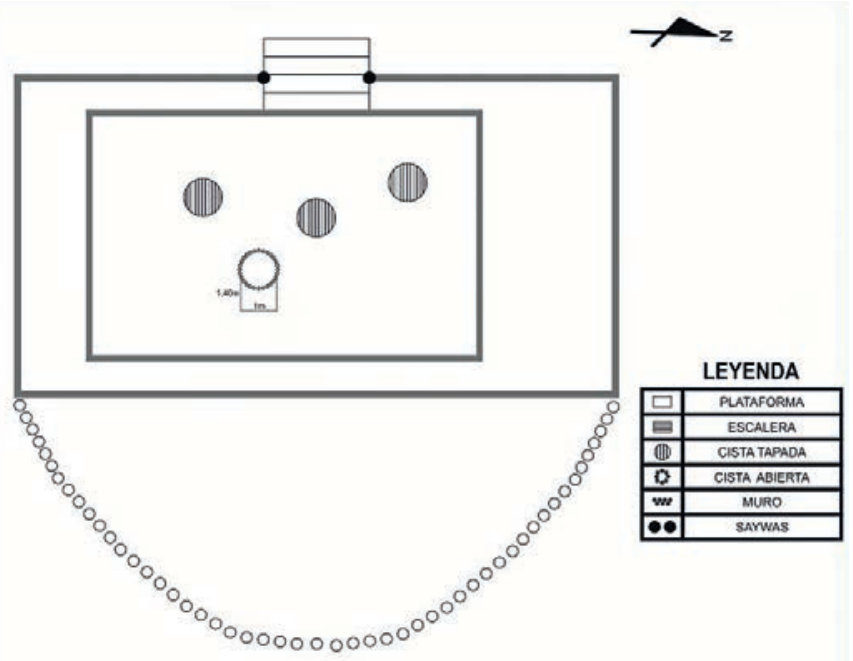

Fig. 14: Croquis del ushnu de Huayna Pizarro se aprecia las 4 cistas y el posible acceso. Dibujo: Abel García

mientras tanto el planeamiento arquitectónico corresponde al modelo propio del Tawantinsuyu. La ausencia de escaleras sugiere la posibilidad de la existencia de una rampa móvil, es decir se ponía y quitaba, antes y después de la ceremonia (Fig 15).

Elementos asociados: está relacionado a un camino antiguo que se proyecta de la ciudad de Ayacucho hacia Andahuaylas y Cusco, desde donde se vislumbra la imponente cuenca del río Pampas; en las inmediaciones hay pequeñas lagunas y corrales ganaderos que sirven de sustento de la población local.

Filiación Cultural: Horizonte Tardío.

Estado de conservación: Regular

Registrado por: Cavero y Gavilán (2008)

\section{EL USHNU DE TORRECHAYUQ}

Ubicación geográfica: se ubica en la cima del cerro Torrechayuq que viene a ser una vertiente de la cadena de montaña Pumaqawanqa. Sus coordenadas son: $13^{\circ} 21^{\prime} 52.82^{\prime \prime}$ S y $73^{\circ} 57^{\prime} 17.60^{\prime \prime}$ o a 4,102 m.s.n.m

Toponimia: es una palabra quechua compuesta que estaría ligada "a la forma piramidal de la estructura".

Ubicación política: Comunidad de San Juan de Ocros, distrito de Ocros - Huamanga.

Acceso: se accede por el sur, partiendo de la carretera de Sillarumi cuesta arriba por la cresta del cerro epónimo; y desde el pueblo de Ocros por un camino antiguo hasta arribar al abra desde donde se percibe el ushnu precitado.

№ de plataformas y acceso: una plataforma /al Oeste

Dimensiones: $18 \mathrm{~m}$ x $12 \mathrm{~m}$ y $1.60 \mathrm{~m}$ de alto. 
Tipo de mampostería: acabado semi-almohadillado

Descripción: se trata de una estructura de forma rectangular que presenta dos plataformas superpuestas de mampostería semi-almohadillado cuya base ha sido levantada en un terreno irregular lo que ha motivado la existencia de dos plataformas para nivelar el piso. La segunda plataforma ha sido elaborada con piedras semicanteadas, por lo que su acabado es ligeramente rustico y se aprecia el uso de mortero de barro entre sus juntas (Fig 17).

Elementos asociados: está relacionado a un camino prehispánico que se proyecta de la ciudad de Ayacucho hacia Andahuaylas y Cusco, desde donde se vislumbra la imponente cuenca del río Pampas; en las inmediaciones hay pequeñas lagunas y corrales ganaderos que sirven de sustento de la población local.

Filiación Cultural: Horizonte Tardío.

Estado de conservación: Regular

Registrado por: Cavero y Gavilán (2008)

\section{INTERPRETACIÓN Y CONCLUSIONES}

En la idiosincrasia andina, las comunidades identifican sus mitos y leyendas con sus deidades "protectoras" que vienen a ser espacios naturales situados en un punto geográfico que poseen un arraigo tradicional de larga data. Lugares como Pumaqawanqa o Huachuya que eran y aun son respetados por la población local, cuya representación está ligada al culto de los "apus" ancestrales, la protección y fecundidad agro-ganadera, la sanación del alcanzo o pacha y la adivinación que son conducidos por los llamados sanadores o sacerdotes3 andinos. Las sociedades prehispánicas que habitaron en la región de Ayacucho y sobre todo los incas, parecen haber definido su vida en función del espacio habitado y sacralización del paisaje (Niles 1992; Bauer 2000); pues diversos elementos eran considerados deidades que permitían organizar y unificar lugares cada vez más distantes a la capital sagrada, Cusco (Campos 2015:149). Es en este espacio donde destacan las huacas4, lugares sagrados destinados al culto y veneración, así como la realización de prácticas oraculares y en algunos casos astronómicos. Estos lugares sagrados tenían múltiples significados (relativamente ambiguas), principalmente están relacionadas a las montañas, cerros, lagunas, cuevas, rocas y animales que representan la manifestación sobrenatural de una entidad espiritual con poderes (Polia 1999:107), que tenían una importancia real y simbólica.

En la cosmovisión andina Waka o Huaca se define como "cualquier cosa o lugar que posee poderes trascendentales” (D’Altroy 2003:174). En efecto, el termino huaca no siempre está referido a los edi-

3 Es importante recordar que en el mundo andino existen tres categorías que diferencian a los sacerdotes andinos: están los "Pongos" (Alto Mesayoq, Camayoq, Yatiris o los Sacerdotes de los Apu Wamanis), "Layqas" (brujos o hechiceros) y los "Hampiqkuna" o "Hampykamayoq" (curanderos o los doctores andinos) son identificados como personajes típicamente de origen andino o campesino, y segundo, porque todos ellos, de una forma o de otra, entran en contacto con los Apu Wamanis o los dioses andinos de las "Montañas Sagradas". Sin embargo, cada cual tienen sus propios métodos y mecanismos de procedimiento para alcanzar los fines y sus funciones sociales; los pobladores andinos son conscientes y acuden a los especialistas según sus necesidades (Arroyo 2006:83).

4 "Huaca constituye un importante término/concepto panandino, común a las dos principales lenguas de los Andes, el qhichwa (waqa) y el aymara (wak'a). En las crónicas y documentos jurídicos del período colonial temprano se usó ampliamente para describir una variedad de lugares y objetos naturales y de obra humana (por ejemplo, divinidades nativas, que incluyen piedras, rocas, montañas, cerros, fuentes, ídolos), los santuarios dedicados a aquellas divinidades y las cuevas y enterratorios en que se encontraban tesoros. Además, se empleó como una categoría de parentesco, y tuvo un uso amplio para referirse a los antepasados lejanos y a los objetos y fenómenos extraños y/o extraordinarios" (Astvaldsson 2004:1-2). 


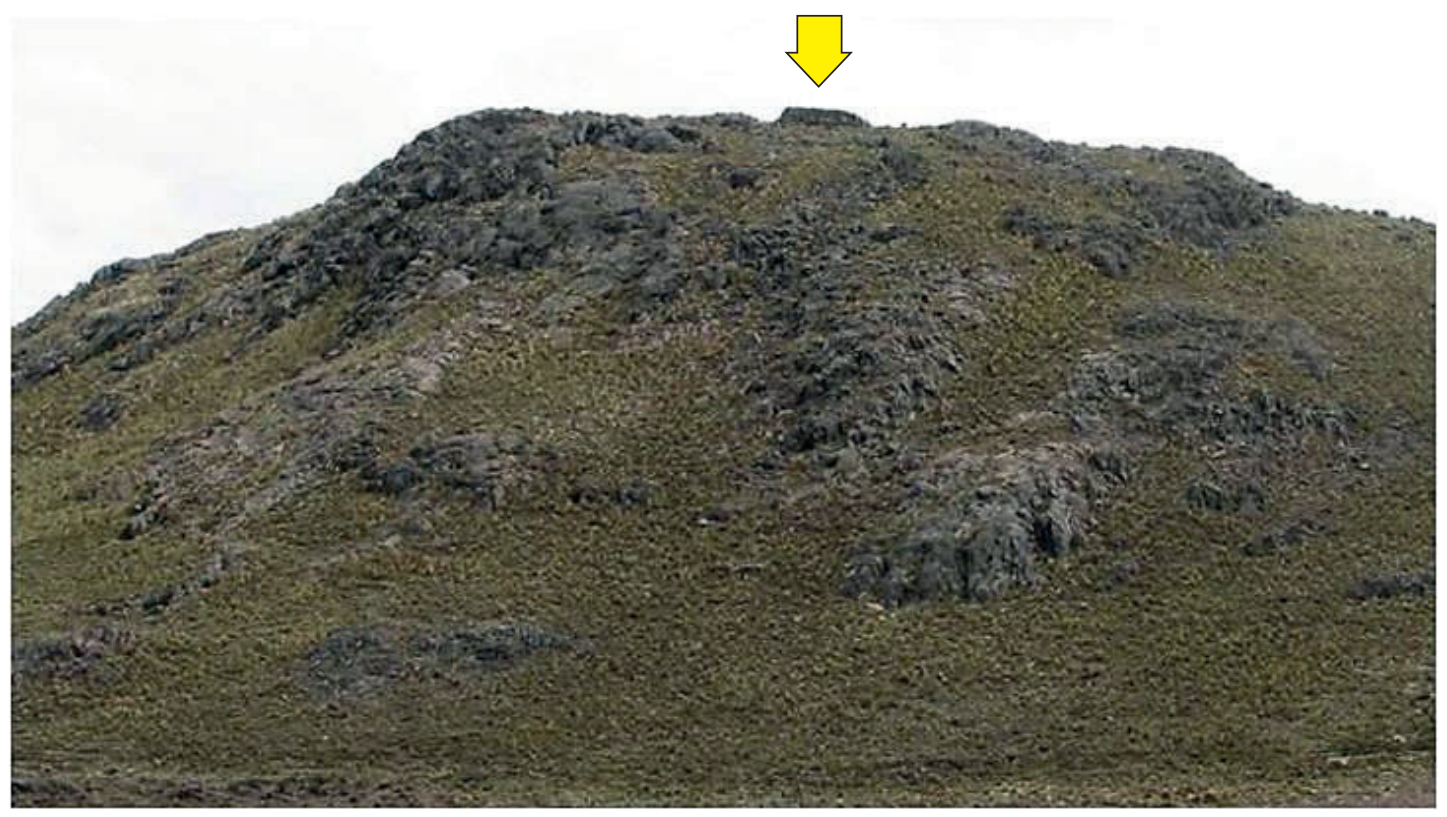

Foto 15-16. Vista del ushnu de Pumaqawanqa situada en la montaña epónima. Abajo. Vista satelital del Ushnu. Fuente: Yuri Cavero y Google Earth.
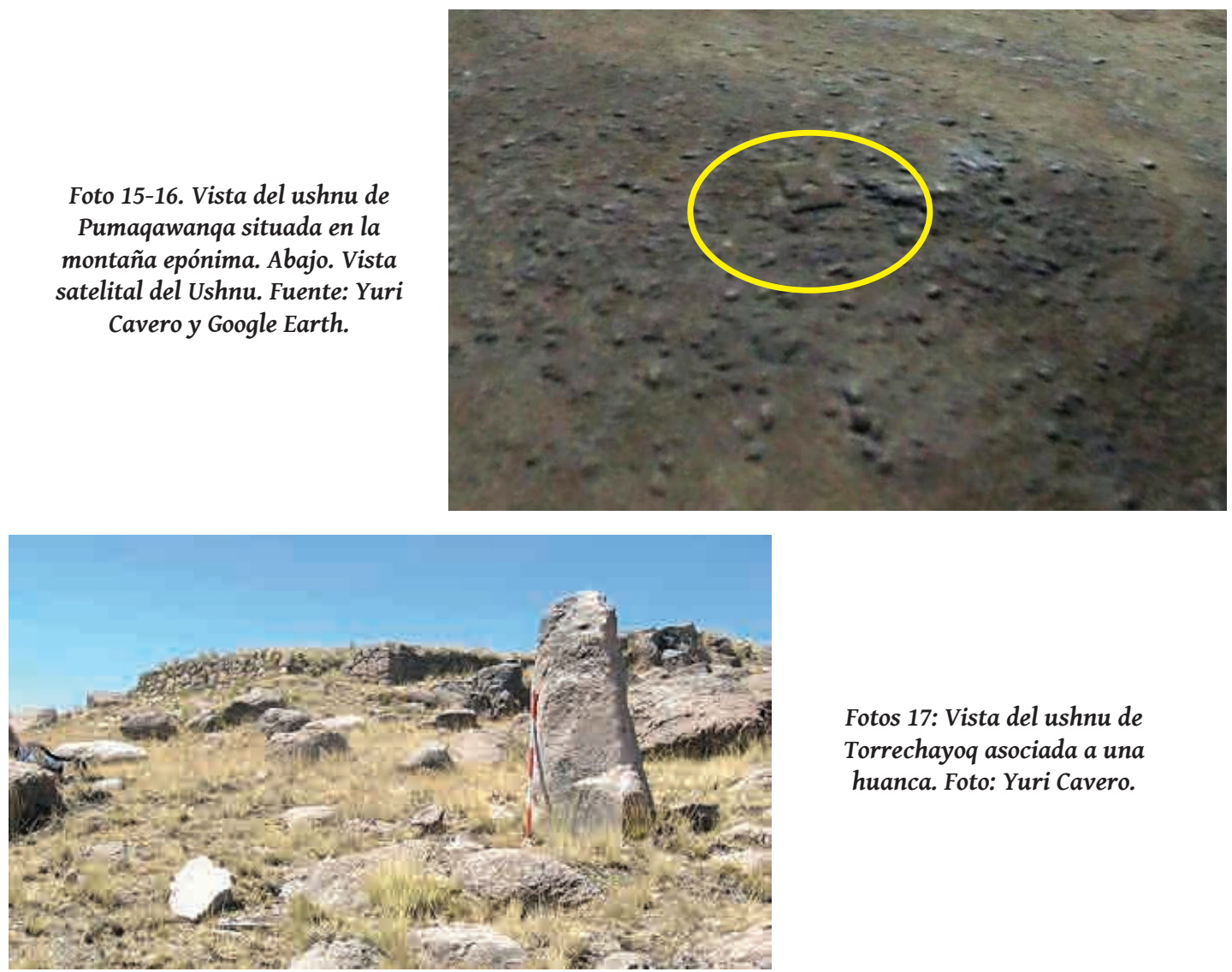

Fotos 17: Vista del ushnu de Torrechayoq asociada a una huanca. Foto: Yuri Cavero. 
ficios construidos sino a los lugares sagrados que poseen personalidad propia y forman parte de los panteones locales, y manteniendo una estrecha relación con el poblador andino. Los ushnus del distrito de Ocros por su correspondiente ubicación y morfología fueron huacas menores que cumplieron la función estratégica de imposición ideológica Inca hacia los grupos locales, y de paso cumplieron funciones relevantes en relación al wamani principal del norte ayacuchano, Razuwillka ${ }^{5}$. Eran estas huacas beneficiarios de ofrendas y pagos de distinta naturaleza, jerarquizados de acuerdo al poder que se le atribuye donde cada comunidad sabe cuáles tienen "mejor mano", y cuál es el pago adecuado que se debe efectuar para que sus peticiones sean atendidas. De ahí la gran valoración que se otorga a las ofrendas y sacrificios dirigidos a los cerros, además de los pagos que, a fin de mantenerlas satisfechas, las comunidades ofrecen a las entidades tutelares que en ellos habitan (Campos 2015:155).

Sobre la existencia de los ushnus en los espacios geográficos aislados e inhóspitos hay opiniones variadas pero que confluyen en una sola idea; fueron lugares sagrados ubicados en la cima de los cerros o wamanis de la puna, sin ninguna asociación con otros tipos de estructuras arquitectónicas, salvo una estrecha relación con el sistema vial el cual lo articula (Cavero 2005, 2015; Vivanco 2004). Espacios que han sido seleccionados cuidadosamente por personas quienes utilizaron como un lugar sagrado para realizar sus ceremonias o evocación a los dioses andinos, y posiblemente los cerros alcanzaron el máximo respeto, en uso del espacio de ahí quizás nace la obediencia a cerros imponentes, y los incas al establecerse construyeron plataformas rectangulares en lugares respetados, para debilitar la religión local Chanca (Vivanco y Meddens 2010). Estas montañas imponentes a los que se refieren serían los apus o wamanis importantes de Ayacucho como Qarwarazu en el sur y Razuwillka en el norte, los santuarios de Osqonta y Sara Sara, y otros cerros imponentes o dioses tutelares de los pueblos; lugares primigenios venerados por las sociedades preincaicas de la región y adoptados por los incas a modo de imposición y triunfo sobre los grupos locales (García 2012:128; Cavero 2015). Tal como los santuarios habrían sido los principales centros de peregrinaje y de culto en la provincia Inca de Vilcashuamán (Cavero 2015:103). En este sentido, las esferas económicas, sociales y rituales de cada sociedad, conformaron un todo significativo que posibilita el orden y manejo de cada espacio sagrado, existiendo lugares más sagrados que otros, por su relación con los antepasados, las montañas, el sol, las fuerzas telúricas, el inframundo o las deidades celestes (Moyano 2006:58). En este contexto, los ushnus del distrito de Ocros fueron huacas de alcance local vinculada con el culto al complejo montañas-fertilidad de la tierra y una relación cumbre-ushnu. La interpretación sobre el particular es aun preliminar.

Estos ushnus se ubican en la cadena de montaña denominada Pumaqawanqa, que viene a ser un espacio geográfico aislado y origen de dos microcuencas de terrenos fértiles y productivos, es lugar donde se originan los ríos Ocros, Qaqamarca y Llaccolla, cuyas aguas son fundamentales para la agricultura. La elección del lugar en el que se construyeron no fue casual, respondería a una astucia Inca al edificar el ushnu sobre una huaca local, la ubicación es estratégica y donde hubo un dominio territorial y de control económico, político y social que se materializó en la sujeción de los apus locales como Huachuya y Qollqe Pedro; además, la presencia Inca en esta zona contrajo el control comercial y de intercambio de productos traídos de otras zonas, de los valles circundantes a la cuenca baja del rio Pampas. Todo este intercambio de productos se debe a la existencia de un camino principal o Qha-

5 Conforma la cadena de la cordillera oriental de los andes centrales, es la montaña más elevada de la región norte de Ayacucho y noreste de Huancavelica. El Apu Razuwillka es un símbolo religioso andino y de recreación cultural con sentido regional cuyo prestigio rebasa más allá de la región de Ayacucho, en las conciencias y actividades de las sociedades rurales de la jurisdicción, sino también por las gentes urbanas intelectuales o de preocupación cultural y aún más, por los trajinantes de caminos (negociantes que integran las localidades y las regiones) y por aquellos que tienen acceso a las tierras, tanto en la sierra como en la selva (Arroyo 2006). 
paq Ñan que atraviesa el valle de noroeste a este, siendo un paso obligado de los viajeros que venían de Cusco hacia Ayacucho y viceversa, pasando sobre el magnífico puente colgante sobre el Pampas (García 2009); finalmente, hasta la fecha no hay registro de sitios con arquitectura Inca en el valle, al contrario se ha identificado material cultural de esta época en asentamientos propios de los chancas y en las cercanías de las casas hacienda coloniales como Ccaccamarca y Occechipa.

Asimismo, existe una diferencia marcada de la técnica constructiva de los ushnus registrados en Ayacucho; hacia el sur, los constructores procuraron copiar la forma de la piedra labrada tipo Inca imperial que exhiben perfectas uniones como los ushnus de Vilcashuamán, de Osqonta 1 y 2, Wamanillo, Mesapata, etc., situados en espacios de suma importancia relacionado al apu Qarwarazu (Cavero 2010; Meddens et. al 2009). Hacia el norte se han identificado ushnus de mampostería rústica o tipo pirca, y parece haber sido realizada por manos no familiarizadas con las elaboradas técnicas incaicas, pero que cumplieron las mismas funciones que sus contrapartes sureños (Valdez 2009; Cavero 2010; García 2012). Quizás obedezca a que los pueblos locales también se hacían presentes con el uso de técnicas o tradiciones propias para la construcción del ushnu, tal como lo plantea Villacorta (2003) para el caso de los ushnus del valle del Rímac, al expresar que estos pudieron haber constituido una rápida y eficiente capacidad de reacción (adecuación) de los curacas locales ante el nuevo orden establecido por los incas. ¿A qué obedecía esta diferencia? la diferencia arquitectónica estaría ligada a la ubicación, mano de obra y sobre todo al prestigio de las montañas o apus tutelares a las que estaban circunscritos; por ejemplo, los elaborados ushnus sureños estaban conexos al apu Qarwarazu, que fue una montaña de importancia o de rango mayor adoptado por los incas como un oráculo estatal, cuyo poder simbólico no sólo controlaba las lluvias y la fertilidad de la tierra, sino también demarcaba territorios y grupos étnicos según sus rangos y jerarquías. Y hacia el norte ayacuchano se halla el apu Razuwillka (rico y poderoso) es concebido como una huaca importante de la región del Chinchaysuyu (Guamán Poma 1980), se trata de una montaña sagrada de rango regional, probablemente a ello responda la poca elaboración de las estructuras ushnu circundantes.

Estas montañas fueron reconocidas, tratadas y ofrendadas como apus tutelares en el Horizonte Tardío y cuyo prestigio aún siguen vigentes como principales wamanis. Sobre la procedencia de los componentes arquitectónicos (relleno estructural y las piedras) de los ushnus, Cavero (2005) y Vivanco et. al. (2010) a partir de las excavaciones efectuadas en algunos ushnus de Ayacucho, confirman que su procedencia no necesariamente fue local sino que en muchos casos fueron acarreados desde las montañas sagradas. Sobre el particular, Kolata (1993) aclara la propuesta al mencionar que desde las cordilleras Quimsachata y Chila trasladaron la tierra para nivelar la pirámide de Akapana; y los reportes de Ogburn (2004) confirman que las piedras de la cantera de Rumicolca en Cusco fueron transportadas hasta Ecuador para ser utilizados en un edificio Inca. Probablemente los materiales constructivos de los muchos ushnus presentes en Ayacucho hayan sido extraídos y trasladados desde las montañas o wamanis sagrados, o huacas locales de los alrededores; posteriores investigaciones darán mayores luces a esta premisa.

Las fuentes etnohistóricas y datos arqueológicos sobre las características arquitectónicas o formales de los ushnus mencionan que, la forma estaría ligada a la concepción de imitación a las montañas a manera de tinkuy donde confluían los tres mundos de la concepción andina hanan pacha, kay pacha y uku pacha (Zuidema 1989; Meddens 1997; Pino 2005). Sobre ella efectuaron ceremonias públicas-religiosas que consistía verter agua6 sobre la tierra, de esta manera se representaba el recorrido simbó-

6 Las fuentes de agua como nevados, lagunas, puquiales, ríos y lluvias eran considerados como sagrados y con frecuencia recibían ofrendas; esta premisa es bastante razonable ya que hay algunos ushnus como de Inkaperqa de Acosvinchos, Atenqocha de Vischongo entre otros, que estarían ligadas a las lagunas y montañas donde se halla la nieve, cuyas aguas hicieron posible el desarrollo de la agricultura, ganadería y otras actividades de los 
lico del agua a través de estos tres planos verticales (Monteverde 2010). Entre los usos y funciones del ushnu también refieren a lo astronómico7, que mantenían una relación directa con los fenómenos del cielo, el solsticio y equinoccios, o con eventos lunares (Vivanco et. al. 2010), que permitieron determinar las fechas importantes para normar e integrar los calendarios agrícolas locales (Zuidema 1989). La propuesta de Ramón (2015) es válido al razonar que fueron altares para el rayo (Yllapa Ushnu o ushnus de la puna), si consideramos que en estos lares ocurren con frecuencia el retumbar de truenos y rayos, que en muchos casos, cobra la vida de personas y animales; es un fenómeno meteorológico temido y respetado por la población local. Para el caso de los ushnus de Ayacucho, hasta la fecha no existe un estudio sistemático afín a la astronomía, son propuestas que suponen la realización de estas actividades en estos sitios, sin embargo ninguno ha demostrado que efectivamente así ocurrió. Por lo tanto, dentro de las interpretaciones de las plataformas ceremoniales con relación a las observaciones astronómicas debería tomarse con mucha discreción al afirmarse tal hipótesis pero tampoco se puede descartar esta posibilidad.

En la plataforma superior del ushnu de Huayna Pizarro, se registró cuatro cistas de forma circular de $1 \mathrm{~m}$ de diámetro y $1.40 \mathrm{~m}$ de profundidad, la presencia de estos elementos en un ushnu hasta el momento no han sido citados, podría tratarse de un sitio atípico con estas características en la región. Al interior de estas estructuras no se han hallado material cultural (cerámica, textiles o restos óseos), podría tratarse de un espacio donde depositaron ofrendas o pagos a los apus tutelares; pero también existe la posibilidad de ser tumbas relacionados al ritual del capac hucha o capacocha (García 2009; 2012, 2015). El uso de los ushnus para los rituales de sacrificios capac hucha o capacocha8, son reportados por Cieza de León (1947[1553]) para el caso de Vilcas donde sacrificaban animales y niños. Guaman Poma (1980) complementa esta tesis al mencionar que los incas reservaban tierras para los sacrificios denominados ushnus. Este ritual marcaba los linderos de las conquistas cusqueñas y confirmaba la posesión de las provincias; estos sacrificios eran reservados solo para las huacas principales y las criaturas sacrificadas se convertían en oráculos que recibían ofrendas y adoración de la población lugareña (Rostworowski 2008). Para el caso ayacuchano, Vivanco (2004) ratifica esta premisa al sugerir que la población del entorno de los ushnus aislados asistía a los cultos con tributos de producción y fuerza de trabajo. ¿En realidad estas ofrendas estaban destinadas al capacocha? Es sabido de la existencia de evidencias de este ritual en las montañas sagradas como Llullaillaco, Sara Sara, etc. (Vitry 2008); e inclusive los hallazgos de restos humanos asociados a ofrendas que podrían representar el sacrificio de capacocha, como en Usno-Moqo en Abancay (Oberti 1997), y en El Shinkal de Quimivil al noroeste argentino (Raffino et. al 1997). Las excavaciones en los ushnus de Ayacucho llevados a cabo por Cavero (2005) y Vivanco et. al. (2010), no registraron evidencia alguna del capacocha, y descartan la posibilidad de la relación del ushnu con el capacocha debido a la ausencia de hallazgos de entierros y ofrendas en los ushnus excavados en Lucanas, Huancasancos y en el norte ayacuchano9.

grupos sociales andinos (García 2012:129).

7 En las inmediaciones de los ushnus de Ocros, especialmente Pumaqawanqa, se ha identificado la presencia de algunas Huancas que confirmarían la propuesta de espacio astronómico.

$8 \mathrm{El}$ sacrificio del capac hucha o el sacrificio de niños se realizaban para que los dioses aseguraran el agua, de esta manera por la trascendencia del agua, la mayoría de las huacas en el Cusco, Vilcashuamán, eran fuentes de agua o estaban relacionados con ellas (Rowe 1979, citado por Santillana 1999: 75).

9 Algunos cronistas resaltan que se llevaron a cabo estas ceremonias en las huacas locales, tal como lo dice Guaman Poma (1980): "Y los demás yndios Chinchay Cochas, Tarmas, Yauyos, Guanuco, Guaylas, Chachapoya, Canari, Cayanpi, Quito, Angarays, Tanquiua, Sora, Lucana, Andamarca, Parinachocha, Quichiua sacrificavan cada uno en sus uacas ydolos que son muy muchos, que por prolixidad no lo pongo. Que a cada destos sacrificavan con criaturas y con oro y plata y ropa, comida y uaxillas de lo que hallauan en todo Chinchay Suyo sus sacrificios" (Guaman Poma 1980 [1583-1613]: 241). 
Hasta el momento no existen argumentos científicos y técnicos que comprueben puntualmente la correspondencia cultural de este ritual en los ushnus de Ayacucho; para el caso puntual de Huayna Pizarro, considero que esta posibilidad es latente debido a las características de la cistas registradas, las particularidades del espacio geográfico circundante compuesto de extensas planicies altoandinas, fértiles valles y apus tutelares circunscritos. Estos últimos fueron venerados desde épocas preincaicas y adoptados por los incas como símbolo de dominio hacia los grupos locales; eran conceptualizados por los pobladores locales como espacios sagrados con poderes especiales.

En general, las observaciones presentes en este artículo son preliminares, se requiere efectuar un trabajo sistemático, especialmente en el ushnu de Huayna Pizarro, con el propósito de determinar la funcionalidad de las cistas presentes allí.

Finalmente, la región de Ayacucho y en especial el distrito de Ocros cuentan con un valioso patrimonio cultural producto de la capacidad creativa e ideológica de sus habitantes, que dejaron como legado para la posteridad. Desde esta perspectiva, está en manos de las instituciones del estado y los decisores políticos locales en velar por la salvaguardia de los ushnus aislados, que por su ubicación es propenso a ser destruido por manos inescrupulosas; proponiendo proyectos y programas de identificación, protección y puesta en uso social de estos recursos culturales, siguiendo las directrices de la legislación y con el asesoramiento técnico especializado.

\section{RECOMENDACIONES}

Para la protección integral y sostenible de los ushnus aislados no puede ser únicamente responsabilidad de las instituciones públicas. Es necesario la integración de los técnicos o gestores culturales y la comunidad. Para ello, son imprescindibles las medidas de sensibilización a la población local, ya que es necesario dar a conocer a sus legítimos beneficiarios la importancia cultural de estas estructuras. La puesta en uso social, se debe cumplir a través de programas educativos y divulgativos, siendo una estrategia eficaz que las propias inversiones en conservación patrimonial.

\section{AgRADECIMIENTOS}

Al colega y amigo Pieter van Dalen Luna por el apoyo desinteresado, a los arqueólogos Alex Zamora, Joel Cárdenas y Juan Bolívar por las salidas al campo; a mi familia y Mary Grisel Gallegos Escajadillo por la motivación.

\section{REFERENCIAS}

\section{ALBORNOZ, Cristóbal}

1989 [1581-1585] "Instrucción para descubrir todas las guacas del Piru y sus camayos y haziendas. Fábulas y mitos de los Inkas. Urbano, Enrique \& Pierre Duviols, crónicas de América, 48. Historia 16. Madrid.

\section{ANGRAND Leonce}

1972 Imagen del Perú en el siglo XIX. Editor Carlos Milla Batres. Barcelona.

AÑANCA, William y CANCHARI, Miguel A.

2009 Prospección arqueológica en la micro cuenca del río Churruwayqu, Chungui-La Mar. Informe para optar el grado de Bachiller en Arqueología. Universidad Nacional de San Cristóbal de Huamanga. Ayacucho - Perú 
ARROYO, Sabino

2006 CULTO A LOS HERMANOS CRISTO, Sistema Religioso Andino y Cristiano: Redes y Formas Culturales del Poder en los Andes. Tesis para obtener el grado de Doctor en Ciencias Sociales: Especialidad de Antropología. Unidad de Postgrado, Universidad Nacional Mayor de San Marcos. Lima.

ASTVALDSSON, Astvaldur

2004 "El flujo de la vida humana: el significado del término/concepto de huaca en los andes". Hueso húmero $\mathrm{N}^{\circ}$ 44, pp.89-112 www.comunidadandina.org/bda/hh44/9EL\%20FLUJO\%20 DE\%20LA\%20VIDA\%20HUMANA.pdf

BAUER, Brian S.

1996 “El desarrollo del Estado Inka”. Estudios y debates regionales andinos N 96. Centro de Estudios Regionales Andinos Bartolomé de las Casas. Cuzco.

1998 Astronomía e Imperio en los Andes. En. Centro de Estudios Regionales Andinos Bartolomé de las Casas. Cuzco.

2000 "El espacio sagrado de los incas. El sistema de ceques del Cuzco". Archivos de Historia Andina $\mathrm{N}^{\circ}$ 33. Centro de Estudios Regionales Bartolomé de las Casas. Cuzco.

CAMPOS, Carlos E.

2015 "Descubriendo una huaca local: Muyllucamac de Lunahuaná". En: Cuadernos del Qhapaq Ñan, año 3, Nº 3. Pp. 148-158. Lima.

CARRERA, Pablo; FARFÁN, Genaro. y Marino GONZÁLEZ

1945/46 Expedición arqueológica en la cuenca del río Pampas. Informe Museo Nacional de Antropología y Arqueología, Lima - Perú.

CAVERO, Yuri I.

2010 Inkapamisan: Ushnus y Santuario Inka en Ayacucho. Mercantil Ayacucho E.I.R.L.

2015 “Ushnus en la provincia de Vilcashuamán”. Peruvian Archaeology Vol. 2, pp.65-109. The Yamagata University Instiute of Nasca.

CHIRINOS, Ricardo y Lucía BORBA

2014 “Qhapaq Ñan, Patrimonio vivo”. En: Arqueología y Sociedad N² 28, pp. 159-176

CIEZA DE LEÓN, Pedro

1947 [1553]. La Crónica del Perú. Biblioteca de Autores Españoles, Historiadores Primitivos de Indias, Ediciones Atlas. Madrid.

CRIADO BOADO, Felipe

1999 "Del territorio al espacio: Planteamientos y perspectivas para la Arqueología del Paisaje". CAPA 6. Criterios y Convenciones en Arqueología del Paisaje. Grupo de Investigación en Arqueología del Paisaje. Universidad de Santiago de Compostela, España.

D'ALTROY, Terence N.

2003 Los Incas. Editorial Ariel España. 
GARCÍA, A. Abel

2009 Reconocimiento arqueológico en la microcuenca del rio Qaqamarca, valle de Ocros - Ayacucho. Informe para optar el grado de Bachiller en Arqueología. Universidad Nacional de San Cristóbal de Huamanga. Ayacucho - Perú

2012 Ushnus: Plataformas ceremoniales Inca en Ayacucho. Tesina para obtener el título de licenciado en Arqueología. Universidad Nacional San Cristóbal de Huamanga. Ayacucho - Perú.

2015 "Arqueología del distrito de Ocros: Asentamientos del Periodo Intermedio Tardío en la microcuenca del rio Qaqamarca, valle de Chumbes-Ayacucho”. Perú. Arqueología y Sociedad N² 29. Pp 107-146. Museo de Arqueología y Antropología, UNMSM. Lima.

GONZÁLEZ, Enrique; COSMÓPOLIS, J. y Jorge LÉVANO

1981 La ciudad Inca de Vilcashuamán. Universidad Nacional San Cristóbal de Huamanga. Ayacucho.

GONZÁLEZ HOLGUÍN, Diego

1952 Vocabulario de la Lengua General de todo el Perú, llamada lengua Quichua del Inca [1608]. Universidad Nacional Mayor de San Marcos, Lima - Perú.

GÓMEZ, Armando

2009 Prospección arqueológica en la ceja de selva del valle de Sivia, Ayacucho. Informe para optar el grado de Bachiller en Arqueología. Universidad Nacional de San Cristóbal de Huamanga. Ayacucho - Perú.

GUAMAN POMA DE AYALA, Felipe.

1980[1615] Nueva crónica y buen gobierno. Tomo I y II. Biblioteca Ayacucho. Transcripción, prologo, notas y cronología Franklin Pease. Impreso en Venezuela.

HYSLOP, John

1990 Inka Settlement Planning. Austin: University of Texas Press.

INSTITUTO NACIONAL DE CULTURA

2005 “Análisis territorial de Vilcashuamán”. En: Informe del Programa Qhapaq Ñan (Campaña 2004), Volumen II. 1ra edición, Lima.

2008 "El Qhapaq Ñan en la ruta de Chinchaysuyu entre Acostambo y Andahuaylas. En: Informe del Programa Qhapaq Ñan (Campaña 2006), volumen V. 1ra Ed. Lima.

LECOQ, Patrice.

2008 “Prospección arqueológica en Chungui-La Mar, Ayacucho: aspecto metodológico". Revista de Investigaciones de la Universidad Nacional de San Cristóbal de Huamanga, Vol. 18, Nro 1. Ayacucho

LUMBRERAS, Luis G.

1974a Las fundaciones de Huamanga hacia una prehistoria de Ayacucho. Primera edición. Editorial nueva educación. 
MATOS, Ramiro

1994 Pumpu: Centro Administrativo Inka de la Puna de Junín. Editorial Horizonte, Perú.

MEDDENS, Frank

1997 “Función y significado del usnu en el Horizonte Tardío”. Tawantinsuyu. Dpto. de Archeology and Antropology, Australian National University. № 3. Pp. 5-14. Traducido al español por José Quinto. Canberra - Australia.

MEDDENS, Frank; BRANCH, Nicholas y Cirilo VIVANCO

2009 "Plataformas usnu a gran altitud en el departamento de Ayacucho-Perú, su estructura y su significado”. Conchopata Revista arqueológica nํ02. Universidad Nacional San Cristóbal de Huamanga. Ayacucho.

MEDDENS, Frank M.; BRANCH, Nicholas P.; VIVANCO POMACANCHARI, Cirilo; RIDDIFORD, Naomi; y, KEMP, Rob.

2008 "High Altitude Ushnu Platforms in the Department of Ayacucho Peru, Structure, Ancestors and Animating Essence". Pre-Columbian Landscapes of Creation and Origin. John E. Staller (Ed.) p.p 315-355. Springer Science+Business Media, LLC., USA.

MENDOZA, Edison M.

2007 Reconocimiento Arqueológico en la Margen Izquierda de los ríos Yanamayu y Pampas, Vilcashuamán. Informe para optar el grado de Bachiller en Arqueología. Universidad Nacional de San Cristóbal de Huamanga. Ayacucho - Perú.

MORRIS, Craig

1999 "La arquitectura del Tahuantinsuyo". Los Incas Arte y Símbolos. Colección Arte y Tesoros del Perú. Fondo Editorial del Banco de Crédito del Perú. Lima - Perú.

MONTEVERDE, Luis Rodolfo.

2010 "La configuración arquitectónica de los ushnus como espacios de libaciones y ofrendas líquidas durante el Tahuantinsuyo”. Bulletin de l'Institut Français d’Études Andines-IFEA, No. 40, pp. 31-80. Lima.

MOYANO, Rodolfo

2010 "El ushnu y la astronomía de Horizonte en Viña del Cerro". Chungara Revista de Antropología Chilena. Volumen 42, № 2: Pp. 419-432. Universidad de Tarapacá. Facultad de Ciencias Sociales Administrativas y Económicas. Departamento de Arqueología y Museología. Chile.

PERALTA, Juan de Mata

1995 Las Tradiciones de Huamanga. Tomo I, Vol. I. Ediciones Grafica N\&R. Ayacucho.

PINO, José Luis

2004 "El ushnu inka y la organización del espacio en los principales tampus de los wamani de la sierra central del Chinchaysuyu”. Chungará. Vol. 36, № 2; Pp. 303-311. Universidad de Tarapacá. Facultad de Ciencias Sociales Administrativas y Económicas. Dpto de Arqueología y Museología. Chile 
2005 "El ushnu y la organización espacial astronómica en la sierra central del Chinchaysuyu". Estudios Atacameños. № 29, pp. 143-161. San Pedro de Atacama - Chile.

POLIA, Mario

1999 La cosmovisión religiosa andina en los documentos inéditos del Archivo Romano de la Compañía de Jesús (1581-1752). Fondo Editorial de la Pontificia Universidad Católica del Perú. Lima.

PULGAR VIDAL, Javier.

1981 Geografía del Perú. Las ocho regiones naturales del Perú. Editorial Universo S.A. 7 ma ed. Lima.

QUISPE, Valerio y W. ROJAS

2010 Reconocimiento arqueológico en la margen izquierda del rio Qatunmayo, Vischongo - Ayacucho. Informe para optar el grado de Bachiller en Arqueología. Universidad Nacional de San Cristóbal de Huamanga. Ayacucho - Perú.

RAMÓN, Gabriel

2015 “Más allá y más arriba del Cuzco. En torno a los ushnus de puna durante el Horizonte Tardío”. Revista Haucaypata, investigaciones arqueológicas del Tahuaninsuyo año 4. № 9, pp. 6-20. Lima.

RAFFINO, Rodolfo; GOBBO, Diego; VÁZQUEZ, Rolando; CAPPARELLI, Aylen; MONTES, Victoria; ITURRIZAGA, Rubén; DESCHAMPS, Cecilia; MANNASERO, Marcelo.

1997 "El ushnu de Shincal de Quimivil". Tahuantinsuyo, una revista internacional de estudios inkas. Vol. 3: 22-39. Brola Press Pty Ltd. Australia.

REGAL, Alberto

1936 Los caminos del Inca en el Antiguo Perú. Editorial San Martí Lima.

RENFREW, Collin y Paul BAHN

1998 Arqueología. Teorías, métodos y práctica. 2da edición. Ediciones Akal, España.

ROSTWOROWSKI, María

2008 “Peregrinaciones y procesiones rituales en los andes”. Adivinación y oráculos en el mundo andino antiguo. Marco Curatola Petrocchi y Mariusz Ziolkowski editores. Fondo Editorial de la Pontificia Universidad Católica del Perú e Instituto Francés de estudios Andinos, UMIFRE 17, CNRS-MAEE. Primera Edición, Pp. 181-204. Lima.

SANTA CRUZ PACHACUTI, Juan de

1993 [1613] Relación de antigüedades deste reyno del Pirú (Estudio y edición de P. Duviols y C. Itier). Lima y Cuzco: I.F.E.A. y C.B.C.

SANTILLANA, Julián

1999 “Andenes, Canales y Paisaje”. Los Incas Artes y símbolos. Colección Arte y Tesoros del Perú. Fondo editorial Banco de Crédito del Perú. Lima - Perú. 
SQUIER, George

1976 [1877] Un viaje por tierras incaicas, crónicas de una expedición arqueológica en 1865. Universidad Nacional Mayor de San Marcos. Lima - Perú.

TARRAGÓ, Myriam y Luis R. GONZÁLEZ

2005 "Variabilidad en los modos arquitectónicos incaicos. Un caso de estudio en el valle de Yocavil (Noroeste Argentino)”. Chungara, Revista de Antropología Chilena. Volumen no 37, Pp. 129-124. Universidad de Tarapacá. Facultad de Ciencias Sociales Administrativas y Económicas. Departamento de Arqueología y Museología. Chile

VALDÉZ, Julio Ernesto

2009 “Los ushnus en las cuencas del rio Huarpa y el rio Torobamba”. Revista arqueológica Warpa. № 14, Pp. 15-22. Huanta - Perú.

VILLACORTA, Luis Felipe.

2003 "Palacios y ushnus: curacas del Rímac y gobierno inca en la costa central”. Boletín de Arqueología PUCP, N 7: 151-187; Lima.

VITRY, Christian

2008 "Los espacios rituales en las montañas donde los inkas practicaron sacrificios humanos". Paisagens Culturais. Contrastes sul-americanos. Universidad de Federal do Río de Janeiro. Escola de Belas Artes. Carlos Terra y Rubens Andrade editores. (Pp 47 - 65). Brasil.

VIVANCO, Cirilo y F. MEDDENS

2010 "Estudio de Usnus del Tawantinsuyo. Espacios sagrados en territorios estratégicos de Ayacucho". Revista de investigaciones, Volumen 18. Numero 2; Pp.: 81 - 93. Oficina de Investigación, Vicerrectorado Académico, Universidad de Huamanga, Ayacucho.

VIVANCO, Cirilo

2004 “Ushnus o lugares sagrados del imperio Inka en Territorio Chanka, Ayacucho (Perú)”. Revista de investigaciones, Año 12, Volumen 12; Pp.: 149 - 160. Oficina de Investigación, Vicerrectorado Académico, Universidad de Huamanga, Ayacucho-Perú.

WIENER, Charles

[1880] 1993 Perú y Bolivia. Instituto Francés de Estudios Andinos, Universidad Nacional Mayor de San Marcos. Lima.

ZUIDEMA, Tom

1989 “Usnu”. Reyes y Guerreros. Ensayos de Cultura Andina. Grandes Estudios Andinos. Fomciencias, Lima - Perú. 
